\title{
Development of the Premature Infant Nose Throat-Model (PrINT-Model)_An Upper Airway Replica of a Premature Neonate for the Study of Aerosol Delivery
}

\author{
STEFAN MINOCCHIERI, JUERG MARTIN BURREN, MARC AUREL BACHMANN, GEORGETTE STERN, \\ JOHANNES WILDHABER, STEFAN BUOB, RALF SCHINDEL, RICHARD KRAEMER, URS PETER FREY, \\ AND MATHIAS NELLE
}

\author{
Departments of Pediatrics [S.M., J.M.B., MAB., G.S., R.K., U.P.F., M.N.], University Hospital Bern, Bern, BE, 3010, Switzerland; \\ Department of Pediatrics [J.W.], Kantonsspital Fribourg, Fribourg, FR, 1700, Switzerland; Institute for Rapid Product \\ Development [S.B., R.S.], University of Applied Sciences, St. Gallen, SG, 9014, Switzerland
}

\begin{abstract}
Clinical efficacy of aerosol therapy in premature newborns depends on the efficiency of delivery of aerosolized drug to the bronchial tree. To study the influence of various anatomical, physical, and physiological factors on aerosol delivery in preterm newborns, it is crucial to have appropriate in vitro models, which are currently not available. We therefore constructed the premature infant nose throat-model (PrINT-Model), an upper airway model corresponding to a premature infant of 32-wk gestational age by three-dimensional (3D) reconstruction of a three-planar magnetic resonance imaging scan and subsequent 3D-printing. Validation was realized by visual comparison and comparison of total airway volume. To study the feasibility of measuring aerosol deposition, budesonide was aerosolized through the cast and lung dose was expressed as percentage of nominal dose. The airway volumes of the initial magnetic resonance imaging and validation computed tomography scan showed a relative deviation of $0.94 \%$. Lung dose at low flow $(1 \mathrm{~L} / \mathrm{min})$ was $61.84 \%$ and $9.00 \%$ at high flow $(10 \mathrm{~L} / \mathrm{min}), p<0.0001$. 3Dreconstruction provided an anatomically accurate surrogate of the upper airways of a 32-wk-old premature infant, making the model suitable for future in vitro testing. (Pediatr Res 64: 141-146, 2008)
\end{abstract}

$\mathrm{L}$ ung disease, especially hyaline membrane disease, causes significant morbidity in preterm newborns (born before $37 \mathrm{wk}$ after the beginning of the last menstrual period) (1). It is currently treated invasively by intratracheal instillation of surfactant (1). Aerosol therapy offers a noninvasive alternative and has the advantage of administering drugs locally to the site of action, thus avoiding systemic effects. Therefore, aerosol therapy may offer a potential therapeutic regimen for lung disease in preterm newborns, as well as for other conditions in which the application of aerosolized drugs such as steroids, $\beta$-mimetics, or prostacyclines is a treatment option. However, aerosol therapy in this age group has so far been proven to be inefficient and inefficacious (2). This may be due to the fact that current delivery devices do not meet the requirements of the specific anatomical and physiologic characteristics of the airways and breathing patterns in this special group of patients (3).

Received September 13, 2007; accepted March 12, 2008.

Correspondence: Stefan Minocchieri, M.D, Department of Paediatrics, Division of Neonatology, University of Bern, Inselspital, Bern, BE, 3010, Switzerland; e-mail: stefan.minocchieri@insel.ch
As in vivo aerosol deposition studies in preterm infants are difficult to perform, there is a need for an in vitro model of the upper airways in this age group. Airway models have proven to be a valuable tool in assessing in vitro aerosol delivery (4-6) and help define the optimal combination of device and drug formulation for aerosol delivery in different age groups.

Several human upper airway casts have been developed to study aerosol deposition $(7,8)$ from infancy to adulthood. Both mathematical and anatomical models have been developed for adults (9-12). They show that the upper airways of adults (nose, mouth, pharynx, and larynx) are an important trap for inhaled aerosols $(10,13-16)$.

Infant airway anatomy and physiology differ considerably from older children and adults. These differences are likely to influence lung deposition, shown by only $<1 \%$ of nominal dose being delivered to the lungs of ventilated infants as opposed to $8-22 \%$ in adults (17). Airway morphometrics change dramatically during the first months of life, as well as breathing patterns, airway resistance, and lung volume (18). Lung deposition of drugs is influenced by all of these parameters (19), altering the trajectory of an aerosol particle through the upper airways into the lungs. However, so far no model is available for preterm infants. Therefore, we developed and characterized the premature infant nose throat (PrINT)-upper airway model of a premature newborn to study aerosol delivery in this age group.

\section{MATERIALS AND METHODS}

Development of airway model. The PrINT airway model was developed in three phases: i) first, a three-planar magnetic resonance imaging (MRI) scan of a preterm infant was performed at the University Hospital of Geneva, Switzerland (imaging phase); ii) second, the airway model was constructed using threedimensional (3D)-printing and a photopolymer termed FullCure 720 (construction phase); iii) third, a high-resolution computed tomography (CT) scan was performed on the airway model, providing data to validate the anatomical accuracy (validation phase). Furthermore, flow-pressure patterns were obtained using an infant lung function testing device (Exhalyzer D, Ecomedics, Dürnten, Switzerland) (20) and aerosol deposition experiments were performed. The study was approved by the local medical ethical review board of the University Children's Hospital of Bern.

Abbreviations: 3D, three-dimensional; CT, computed tomography 

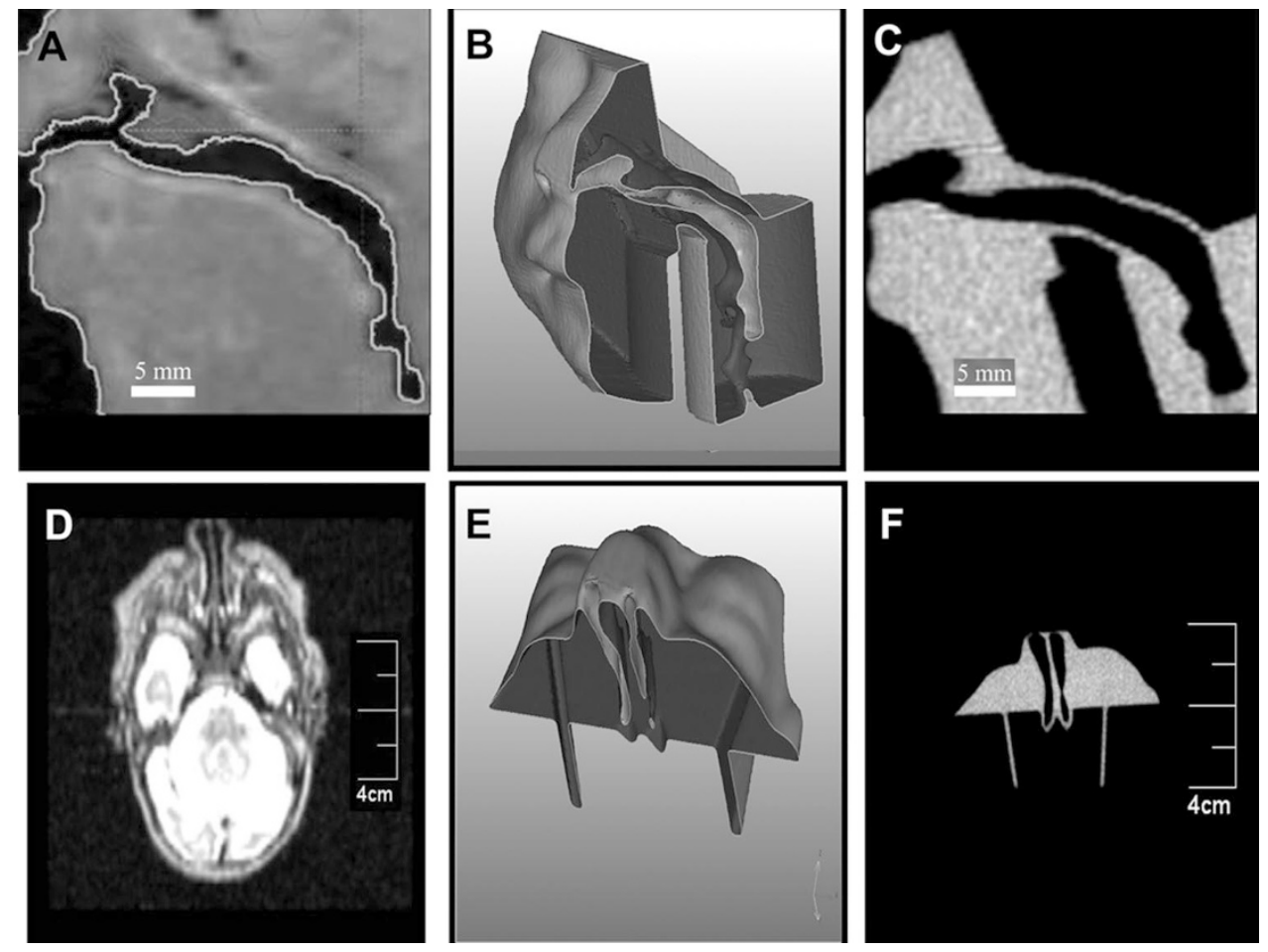

Figure 1. Two-dimensional visual comparison of a selected $(A-C)$ sagittal and $(D-F)$ transversal cross-section through the upper airway; $(A)$ the original MRI data from the infant, $(C)$ the control CT scan of the constructed upper airway model. (B) Shows the corresponding STL file at the section position through the left nostril down to the larynx. $(D-F)$ show an axial cross section through the nose, $(D)$ the original MRI data file, $(F)$ the control CT scan, and $(E)$ the corresponding STL file. The highlighted line in A corresponds to the air-mucosa border.
Imaging. The model was constructed from an MRI (Avanto, 1.5 Tesla, Siemens Medical Solutions, Erlangen, Germany) data set acquired from a healthy male premature infant, with a gestational age of $32 \mathrm{wk}$ (length: $34 \mathrm{~cm}$; weight: $1750 \mathrm{~g}$ ), who underwent the above mentioned investigation in the context of a brain development imaging study (21). The child was sedated, lying in supine position and breathing spontaneously. The duration for the MRI data acquisition was $40 \mathrm{~min}$.

Acquisition of the primary MRI data were achieved using two different imaging modes: a 3D Fourier-transforming fast gradient recalled sequence (1.5-mm coronal slices, flip angle $25^{\circ} \mathrm{C}$, repetition time $15 \mathrm{~ms}$, echo time 4.4 $\mathrm{ms}$, field of view $18 \mathrm{~cm}$, matrix $256 \times 256$ ) and a double-echo (proton density and $\mathrm{T} 2$-weighted) spin-echo sequence (1.5-mm coronal slices, repetition time $3500 \mathrm{~ms}$, echo times 30 and $150 \mathrm{~ms}$, field of view $18 \mathrm{~cm}$, matrix $256 \times 256$, interleaved acquisition). The volume of pixel (voxel) dimensions for both acquisitions was $0.7 \times 0.7 \times 1.5 \mathrm{~mm}$. The slices were then transferred to an imaging workstation for additional 3D and multiplanar reconstructions using Mimics, and Magics Software (Materialise, Munich, Germany).

Reconstruction. Reconstruction took place at the Institute for Rapid Product Development at the University of Applied Sciences in St. Gallen, Switzerland. Optimal negative and positive gray scale thresholds were selected for each slice of the original MRI (coronal slices), stored as a Digital Imaging and Communications in Medicine-Format (DICOM), to provide maximal accuracy of air-mucosa distinction (Fig. 1). Subsequently, the slices were joined together to compose a $3 \mathrm{D}$ reconstruction image, which was stored in Standard Transformation Language (STL) format, and transferred over local area network (LAN) to the fabrication devices. The generated STL file also allowed us to define a choice of sagittal, coronal, and axial cross-sections of the model.

We constructed two models using a photopolymer resin (PolyJet FullCure 720, Objet Geometries Ltd., Sint-Stevens-Woluwe, Belgium), a transparent, stiff material widely used in rapid product development techniques on an Objet Eden 330 3D Printer (Objet Geometries, Rehovot, Israel). Printing layer thickness was $0.016 \mathrm{~mm}$. Of this material, we built one model showing the entire head's surface (Fig. $2 A$ ) and a reduced laboratory model (Fig. 2B-D), consisting of the face and air conducting parts only to conduct all further tests. Anatomical structures included in both models were all air conducting parts from the nostrils to $4 \mathrm{~mm}$ below the glottis.

Validation. A CT scan (Philips Brilliance 16P, Philips Medical Systems, Cleveland, $\mathrm{OH}$ ) was performed on the airway model (voltage: $90 \mathrm{kV}$, current: $95 \mathrm{~mA}$ ) with a slice thickness of $0.8 \mathrm{~mm}$. Both the original MRI and the model CT scan data sets underwent comparison using Materialise Magics, and Mimics software, achieved by two methods. First, a slice per slice comparison was done optically followed by measurements of landmarks. Then a calculation of airway volumes and cross-sectional areas was performed. To facil-
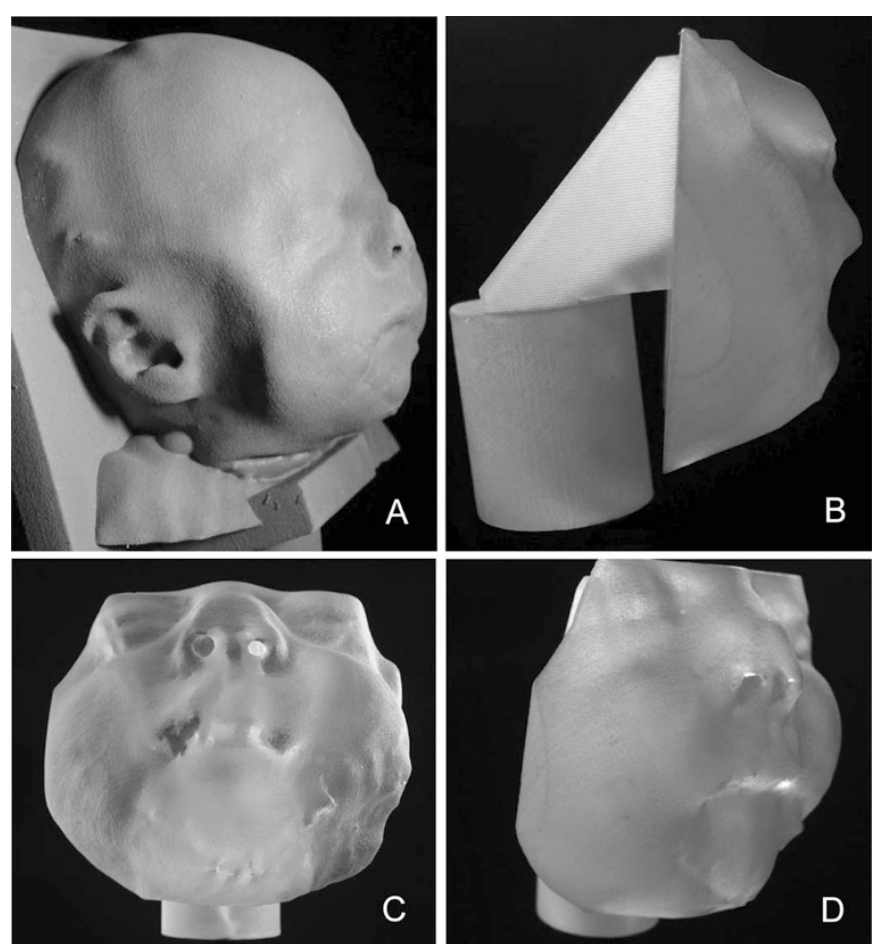

Figure 2. (A) Side view of the complete upper airway model; $B, C$, and $D$ show a lateral, up-front and side view of the reduced laboratory model (face and air conducting parts), all built in FullCure 720.

itate the comparison, limiting cross-section planes were defined behind the nostrils and below the glottis providing specific anatomical landmarks. Deviations in volume of less than $1 \%$ were defined as highly accurate.

A flow-resistance profile through the air conducting part was done using the constructed preterm upper airway model and an Infant Pulmonary Lung function Testing System Exhalyzer D Infant (Ecomedics, Dürnten, Switzerland), which was calibrated according to the procedure described by the European Respiratory and American Thoracic Society Task Force (20). As the 
intention was to assess the model's physical properties and not in vivo physiologic conditions, we carried out measurements that included pressure and flow values exceeding a preterm infant's range. To record the flowresistance profile in inspiration, a face mask (Laerdal Infant Silicon Mask 0/1, Laerdal Medical, Germany) was attached to the airway model using therapeutic putty to ensure an airtight fit on the nonflexible surface of the airway model. Attached to the facemask were a pressure transducer and an ultrasonic flowmeter (Spiroson, Ecomedics, Dürnten, Switzerland), followed by an air-supply tube and a variable air valve. The air flow regulator was subsequently set to randomly chosen, increasing values, beginning at a flow of zero $1 /$ min eventually reaching a maximum value of $18.8 \mathrm{~L} / \mathrm{min}$ corresponding to pressure values of 0 and $11.1 \mathrm{kPa}$, respectively.

Second, the set-up was changed using the subglottic opening at the air entrance, hence simulating the expiratory pathway. Therefore, the measurement and air-supply setup was placed at the caudal end of the model connected by a 22F-T-piece-connector (No. 1983, Intersurgical, Wokingham, UK) to ensure an airtight link to the model. Again, flow-pressure measurements were done as previously described. The airflow ranged from 0 up to $18.6 \mathrm{~L} / \mathrm{min}$ corresponding to a pressure of 0 and $11.5 \mathrm{kPa}$, respectively.

Feasibility of aerosol deposition experiments. As an example, we measured aerosol delivery of a typically used drug, Budesonide solution (Budeflow, PARI $\mathrm{GmbH}$ Starnberg, Germany), from a perforated vibrating membrane nebulizer (e-Flow, PARI GmbH Starnberg, Germany) attached to our airway model with a facemask (Laerdal Neo, model 0, Laerdal Medical, Germany). The Budesonide solution was specifically developed for use with perforated membrane devices. Particle size as measured by the manufacturer shows a mass median diameter (MMD) of $3.12 \mu \mathrm{m}$ with a geometric SD (GSD) of 1.9.

The nebulizer was connected directly to the face mask to reduce the dead space to a maximum of $4 \mathrm{~mL}$ and then attached to the upper airway model using Parafilm (Pechiney, Chicago) to ensure a tight fit. Air tightness was tested before and after each run by using a water column allowing $\pm 1 \mathrm{~cm}$ $\mathrm{H}_{2} \mathrm{O}$ per minute. Ambient air was kept constant at $23^{\circ} \mathrm{C}$ and $50 \%$ humidity. The air in the bypass-flow-system supplying the impactor was also kept constant at $23^{\circ} \mathrm{C}$ and a humidity of $50 \pm 5 \%$.

The model was connected to a Next Generation Pharmaceutical Impactor (NGI, MSP Corp. Shoreview, MN) whose temperature was constantly measured and maintained at $23^{\circ} \mathrm{C}$, with a driving flow of $15 \mathrm{~L} / \mathrm{min}$.

Constant inspiration was simulated with flows of 1,5 and $10 \mathrm{~L} / \mathrm{min}$ through our model to evaluate lung dose. Constant nebulization was performed until depletion of nebulizer. Each experiment was repeated six times.

Budesonide concentration was measured using HPLC. Emitted dose was defined as total amount of drug emitted by the nebulizer. Lung dose was defined as amount of drug recovered in the impactor and expressed as percentage of emitted dose. Nominal dose was defined as total amount of drug filled in to the nebulizer.

Statistical analysis. Statistics were carried out using analysis of variance (StatView 512+; Abacus Concepts Inc, Berkeley, USA) with a significance level of $95 \%(p<0.05)$.

\section{RESULTS}

Modeling and validation. The final upper airway model is shown photographically in Figure $2 B-D$. Figure 1 shows a visual comparison between the $\mathrm{CT}$ scan $(C)$ of the model and the original MRI scan $(A)$, for illustration the STL file $(B)$ is provided at the corresponding section position. For real volume comparison, 3D reconstruction was done (Fig. 3).

The airway volume within the original MRI was $1277 \mathrm{~mm}^{3}$ and that of the CT scan of the model built in FullCure 720 was $1265 \mathrm{~mm}^{3}$ (Fig. 3). These values showed an absolute difference in volume of $12 \mathrm{~mm}^{3}$, which was equivalent to a relative deviation of $0.94 \%$. Their discrepancy in diameter with a mean aberration of approximately $0.03 \mathrm{~mm}$ is not shown.

Flow characteristics and resistance of cast. Fig. 4 shows corresponding pressure values to each applied flow. The pressure slopes prove to be nonlinear, representing square functions (Inspiration: $\mathrm{y}=143.08 \mathrm{x}^{2}-12.16 \mathrm{x}+0.67$; Expiration: $\mathrm{y}=\left(137.64 \mathrm{x}^{2}-7.1721 \mathrm{x}+0.26\right)^{-1}$, coefficients of determination $\left(r^{2}\right)$ are 0.9988 and 0.9994 , respectively). Mean upper airway resistance was $20.5 \mathrm{~cm} \mathrm{H}_{2} \mathrm{O} \cdot 1^{-1} \cdot \mathrm{s}$ (range: 5.8-36.7)

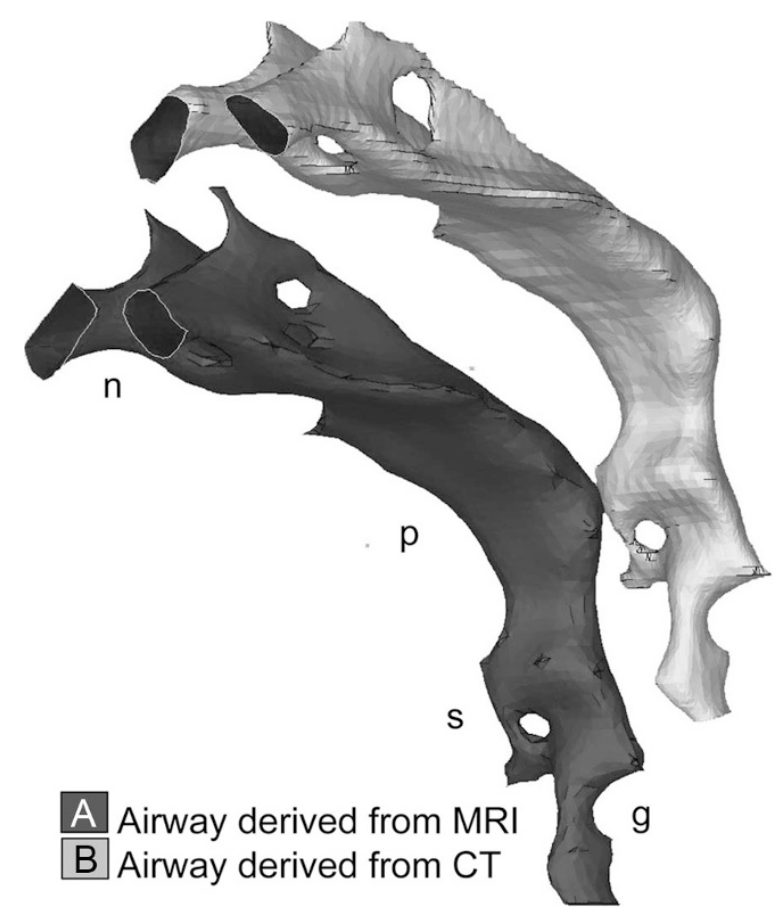

Figure 3. 3D-Validation of cast geometry: Extracted air conducting parts of (A) the original MRI data file and $(B)$ control CT scan of the cast. For volume calculation, limiting section planes were introduced at the nostrils (n) and below the glottis (g). Further shown are the pharynx (p), the piriform sinus (s), and the trachea $(\mathrm{t})$. The difference in volume was $<1 \%$.

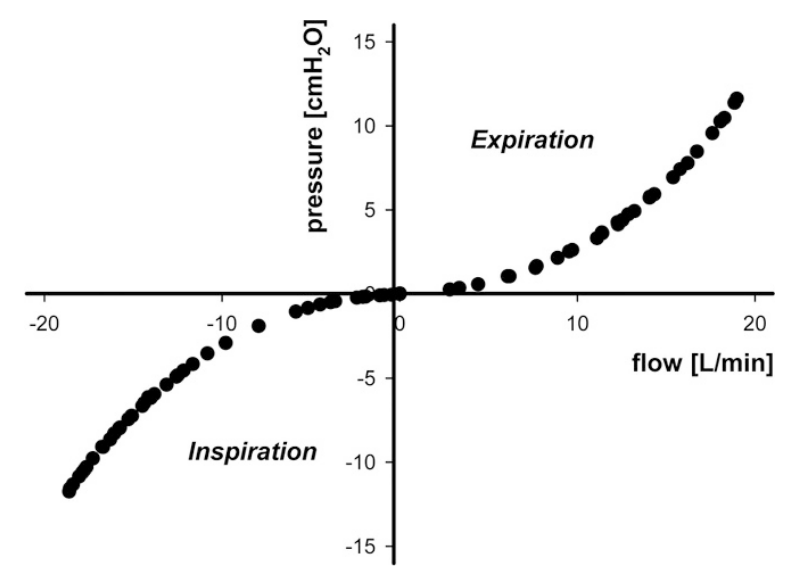

Figure 4. Resistance profile within the PrINT model for inspiratory and expiratory flows.

for the inspiratory, and $23.1 \mathrm{~cm} \mathrm{H}_{2} \mathrm{O} \cdot 1^{-1} \cdot \mathrm{s}$ (range: 4.2-37.9) for the expiratory pathway.

Feasibility of aerosol deposition measurements. Increasing constant inspiratory flow resulted in a decrease in lung dose (Fig. 5).

Lung dose decreased with increasing flow from $61.8( \pm 5.3)$ $\%, 26.0( \pm 1.5) \%$ to $9.0( \pm 0.8) \%$ of nominal dose at 1,5 , and $10 \mathrm{~L} / \mathrm{min}$, respectively. The differences were statistically significant $(p<0.001$ for each measurement condition). Drugrecovery was $86.7,77.0$, and $79.9 \%$ of the nominal dose for 1 , 5 , and $10 \mathrm{~L} / \mathrm{min}$, respectively.

\section{DISCUSSION}

Based on MRI data obtained from a premature neonate of 32-wk gestational age, we developed an anatomically correct 


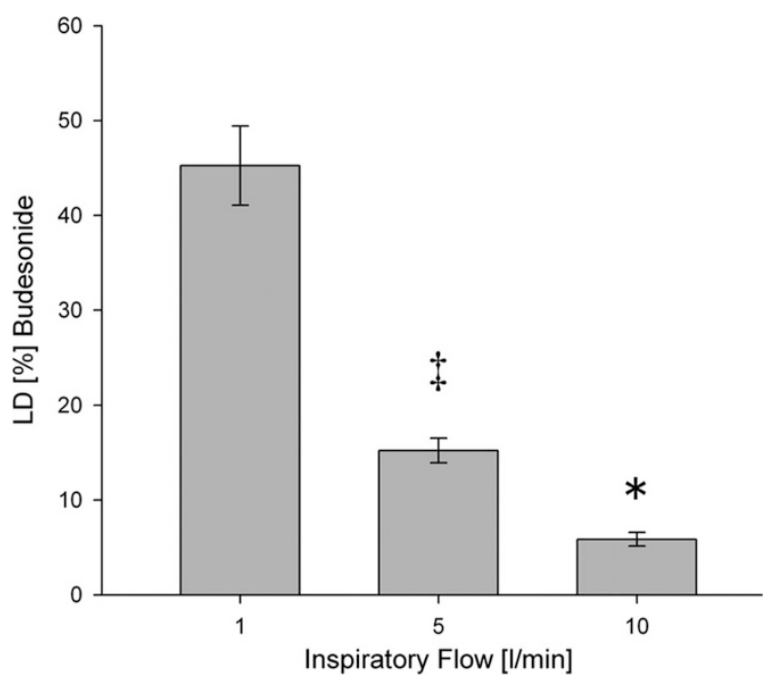

Figure 5. Lung dose (LD) for budesonide, expressed as percentage of nominal dose (ND). Displayed are mean values and error bars in SD, $\$$ and * $p<0.001$ ( 1 vs $5 \mathrm{~L} / \mathrm{min}, 5$ vs $10 \mathrm{~L} / \mathrm{min}$, respectively).

model of the upper airways to study in vitro aerosol delivery. The cast's highly nonlinear flow characteristics and the feasibility of measuring flow-dependent drug delivery into the airways could be demonstrated. To our knowledge, this is the first description of a premature infant upper airway model and its suitability for aerosol studies so far.

The overall goal in inhalation therapy is to deliver medication to the bronchopulmonary tree and lower airways, avoiding deposition in the upper airway tract. Generally, for simulation of aerosol distribution in the respiratory tract, a geometric model of the upper airways is used, the United State Pharmacopoeia (USP) throat, and for the lower airways, the Andersen cascade impactor. Both are designed for simulation of aerosol deposition patterns in adults. The USP throat is a $90^{\circ}$ bent tube with a smooth inner surface, assuming that the adult patient inhales via a mouthpiece. As infants inhale via the nose, and upper airways geometry differs not only in dimensions but also in proportion from those of adults, this model is not suitable for studying aerosol deposition in newborn infants. Furthermore, in a number of in vitro studies $(4-6,22,23)$ it has been pointed out, that the use of a realistic human upper airway replica would be preferable to the USP throat. The main reason, why anatomically correct upper airway models are of interest is that the upper airways act as an important trap for inhaled aerosols $(10,14,16,24,25)$. Aerosol deposition occurs mostly in the larynx and trachea (26,27), and is determined by pharyngeal and glottal morphologic constrictions and consequent flow jets (28). It is therefore imperative to have realistic in vitro models of the upper airways including the larynx and tracheal opening.

The SAINT model, an upper airway model of a 9-mo-old infant, described by Janssens et al. (4), served as master for our work. The model is derived from a CT scan and reconstructed using stereolithography. In contrast to the already existing upper airway model of Phalen et al. (14), which was an extrapolated simplification of an adult nose model by reducing adult airway dimensions by $50 \%$, this model was the first realistic upper airway model of a 9-mo-old infant to correctly represent the anatomy of the upper airways, including the laryngeal part and specifically taking into account nose breathing. The model includes the face, nasal cavity, and pharynx extending to the subglottic region. The nasal airway is open for air passage whereas the oral airway is closed. It has been used in many different studies and is well established $(6,23,29-31)$. In contrast to the above mentioned model, we derived our model from a MRI dataset of a preterm infant, used a different material, and performed aerosol experiments, which can be used for quality assessment.

As model reconstruction is based on an imaging dataset, the quality of data-transposition is crucial. Because of ethical considerations (high radiation), we did not perform CT on a preterm infant, although image resolution and acquisition time would have been preferable. Our dataset consisted of an MRI with limited resolution due to voxel size and comparatively long acquisition time. There are studies in adults $(22,23)$ describing successful evaluation of the upper airways using respiratory-gated MRI to evaluate airway dynamics during tidal breathing, allowing a better distinction of the air mucosa border. However, this technique is not yet established in preterm neonates. Therefore, the manual definition of the optimal threshold for air mucosa distinction is the most critical point in the reconstruction process in our model. The accuracy of this step can only be judged by indirect measurements of physiologic data. Our measurement of an upper airway volume in our model of $1.27 \mathrm{~mL}$ is consistent with the anatomic and physiologic dead spaces of $1-2 \mathrm{~mL} / \mathrm{kg}$ reported in other studies $(32,33)$, which are between. In our infant, with a birth weight of $1750 \mathrm{~g}$, the estimated dead space would be expected to be between 1.75 and $3.5 \mathrm{~mL}$. We only measured the upper airways from the nostrils down to $4 \mathrm{~mm}$ below the glottis, excluding the trachea and bronchi, accounting for the difference between measured and expected volume. The airway resistance measured within our model was at the upper end of the reported range for nasal resistance in Caucasian children weighing between 1.5 and $10.2 \mathrm{~kg}$ (34), supporting the hypothesis that our geometrically identical in vitro model is also comparable in flow-resistance behavior with in vivo measurements. The relatively high resistance can be explained by the additional resistance of pharynx and larynx as well as the rigid, nonexpandable geometry of our model. In vivo, the upper airway geometry changes during tidal breathing, but simulation of dynamically changing geometry is technically difficult. These findings underline the assumption that the reconstruction process was anatomically correct and within the physiologic range.

The aerosol deposition measurements were conducted with the intention to provide a quality assessment tool to guarantee consistency of the aerosol filtering behavior of the model, to be applied as pre- and postexperiment calibration. Therefore, the applied flows were chosen arbitrarily within the range of published maximal expiratory flows during forced expiration in newborns of about $6 \mathrm{~L} / \mathrm{min}$ in (35), and from unpublished observations (U. Frey, personal communication) in preterm infants during clinical routine lung function testing, quiet sleep, and tidal breathing with peak tidal flows of $3.9 \mathrm{~L} / \mathrm{min}$ (range $2.5-6.5 \mathrm{~L} / \mathrm{min}$ ). Although, dead space is not relevant 
during constant inspiratory flow experiments, we took great care to design experiments in a manner usable for further aerosol deposition studies and according to the experiments previously described by Janssens et al. (4). Our data showed the expected reciprocal dependency between inspiratory flow and lung dose due to higher inertial impaction of aerosol particles in the upper airways, resulting in decreasing aerosol penetration to the lower airways. This may be due to secondary flow structures that arise in areas of higher inertial forces (transitional-to-turbulent flow), complicating flow structures as well as aerosol transport and deposition. Computation fluid dynamic simulations of the upper airways in adults have shown that secondary flow structures arise as early as in the nostrils, in-part contributing to the development of turbulent flow structures in upstream airway sections, such as the glottis, leading to deposition of aerosols in the airway wall in these regions $(36,37)$. Increasing inspiratory flows resulted in a lower lung dose.

This finding is in good agreement with other studies using upper airway cast models $(4,6,30)$. In an in vitro study by Schuepp et al. (30), using the SAINT model and the same nebulizer-drug combination we used, lung doses, calculated as percentage of emitted dose, were in the range of 7.9$42.3 \%$. In contrast to the sinusoidal breathing patterns they applied, we used constant inspiratory flows (no expiration). Assuming that half the time of a breathing cycle is expiration, a comparison of their lung doses with our results was only possible if we divided our results by two (corrected range 4.5-30.8\%). Therefore, we concluded that lung dose in preterm infants is less than in a 9-mo-old child.

As the authors state themselves, the material used to build the SAINT model (Stereocol) interfered with the HPLC signal during wash out using ethanol, impeding direct determination of upper airway deposition from direct wash out of the cast (4). We have tested FullCure 720 extensively for solubility behavior with ethanol and methanol. By washing out the airways five times with $10 \mathrm{~mL}$ of methanol, we could detect extractable material from the final cast that could potentially interfere with the budesonide analysis. The error introduced by this was estimated to be around $3 \%$ and was considered acceptable for the purpose of the measurements conducted here. By soaking the model in methanol over $24 \mathrm{~h}$, we detected unacceptably high levels of extracted material, leading us to the conclusion to limit rinsing to a maximum of five times with $10 \mathrm{~mL}$ of methanol. Furthermore, the minimal aberrations in the geometry from the original data, proven to be highly accurate by the validation process comparing anatomical landmarks, distances, and relative deviation in airway volume of $0.94 \%$, endorsed our material selection.

In conclusion, we described an anatomically correct preterm infant nose throat-model and showed that this model may be used for realistic in vitro aerosol experiments; allowing obtainment of in vitro information, which is difficult or impossible to obtain in vivo. Inhaled therapy in preterm infants is difficult and may be improved by designing new inhalation devices and patient-interfaces. Further work on the influence of different breathing patterns and applied aerosol particle sizes on lung deposition would be an important step in im- proving aerosol therapy in the highly vulnerable group of premature infants with drugs such as topical steroids, prostacycline, or lung surfactant.

Acknowledgments. We thank Dr. M. Tservistas and Dr. M. Keller from Pari for their technical support and Prof. P. Huppi and Dr. G. Lodygensky from the University of Geneva for providing MRI data sets of different neonatal upper airways as well as Dr. Jane McDougall for proofreading the manuscript and Dr. Rahel Minocchieri for her assistance during data acquisition.

\section{REFERENCES}

1. Mazela J, Merritt TA, Finer NN 2007 Aerosolized surfactants. Curr Opin Pediatr 19:155-162

2. Berggren E, Liljedahl M, Winbladh B, Andreasson B, Curstedt T, Robertson B, Schollin J 2000 Pilot study of nebulized surfactant therapy for neonatal respiratory distress syndrome. Acta Paediatr 89:460-464

3. Cole $\mathrm{CH} 2000$ Special problems in aerosol delivery: neonatal and pediatric considerations. Respir Care 45:646-651

4. Janssens HM, de Jongste JC, Fokkens WJ, Robben SG, Wouters K, Tiddens HA 2001 The Sophia Anatomical Infant Nose-Throat (Saint) model: a valuable tool to study aerosol deposition in infants. J Aerosol Med 14:433-441

5. Cheng YS, Fu CS, Yazzie D, Zhou Y 2001 Respiratory deposition patterns of salbutamol pMDI with CFC and HFA-134a formulations in a human airway replica. J Aerosol Med 14:255-266

6. Janssens HM, De Jongste JC, Hop WC, Tiddens HA 2003 Extra-fine particles improve lung delivery of inhaled steroids in infants: a study in an upper airway model. Chest 123:2083-2088

7. Srichana T, Martin GP, Marriott C 2000 A human oral-throat cast integrated with a twin-stage impinger for evaluation of dry powder inhalers. J Pharm Pharmacol 52:771-778

8. Saijo R, Majima Y, Hyo N, Takano H 2004 Particle deposition of therapeutic aerosols in the nose and paranasal sinuses after transnasal sinus surgery: a cast model study. Am J Rhinol 18:1-7

9. Cheng KH, Cheng YS, Yeh HC, Swift DL 1997 An experimental method for measuring aerosol deposition efficiency in the human oral airway. Am Ind Hyg Assoc J 58:207-213

10. Martonen TB 1993 Mathematical model for the selective deposition of inhaled pharmaceuticals. J Pharm Sci 82:1191-1199

11. Velasquez DJ, Gabrio B 1998 Metered dose inhaler aerosol deposition in a model of the human respiratory system and a comparison with clinical deposition studies. J Aerosol Med 11:S23-S28

12. Sturm R, Hofmann W 2005 3D-Visualization of particle deposition patterns in the human lung generated by Monte Carlo modeling: methodology and applications. Comput Biol Med 35:41-56

13. Becquemin MH, Swift DL, Bouchikhi A, Roy M, Teillac A 1991 Particle deposition and resistance in the noses of adults and children. Eur Respir J 4:694-702

14. Phalen RF, Oldham MJ, Mautz WJ 1989 Aerosol deposition in the nose as a function of body size. Health Phys 57:299-305

15. Schwab JA, Zenkel M 1998 Filtration of particulates in the human nose. Laryngoscope 108:120-124

16. Swift DL 1989 Age-related scaling for aerosol and vapor deposition in the upper airways of humans. Health Phys 57:293-297

17. Rubin BK, Fink JB 2001 Aerosol therapy for children. Respir Care Clin N Am 7:175-213, v

18. Laine-Alava MT, Minkkinen UK 1997 Variation of nasal respiratory pattern with age during growth and development. Laryngoscope 107:386-390

19. Roth AP, Lange CF, Finlay WH 2003 The effect of breathing pattern on nebulizer drug delivery. J Aerosol Med 16:325-339

20. Frey U, Stocks J, Coates A, Sly P, Bates J 2000 Specifications for equipment used for infant pulmonary function testing. ERS/ATS task force on standards for infant respiratory function testing. European respiratory society/American thoracic society. Eur Respir J 16:731-740

21. Lodygensky GA, Rademaker K, Zimine S, Gex-Fabry M, Lieftink AF, Lazeyras F, Groenendaal F, de Vries LS, Huppi PS 2005 Structural and functional brain development after hydrocortisone treatment for neonatal chronic lung disease. Pediatrics 116:1-7

22. Ross DL, Gabrio BJ 1999 Advances in metered dose inhaler technology with the development of a chlorofluorocarbon-free drug delivery system. J Aerosol Med 12:151-160

23. Janssens HM, Krijgsman A, Verbraak TF, Hop WC, de Jongste JC, Tiddens HA 2004 Determining factors of aerosol deposition for four pMDI-spacer combinations in an infant upper airway model. J Aerosol Med 17:51-61

24. Diot P, Palmer LB, Smaldone A, DeCelie-Germana J, Grimson R, Smaldone GC 1997 RhDNase I aerosol deposition and related factors in cystic fibrosis. Am J Respir Crit Care Med 156:1662-1668 
25. Svartengren K, Lindestad PA, Svartengren M, Bylin G, Philipson K, Camner P 1994 Deposition of inhaled particles in the mouth and throat of asthmatic subjects. Eur Respir J 7:1467-1473

26. Mallol J, Rattray S, Walker G, Cook D, Robertson CF 1996 Aerosol deposition in infants with cystic fibrosis. Pediatr Pulmonol 21:276-281

27. Lin CL, Tawhai MH, McLennan G, Hoffman EA 2007 Characteristics of the turbulent laryngeal jet and its effect on airflow in the human intra-thoracic airways. Respir Physiol Neurobiol 157:295-309

28. Brouns M, Verbanck S, Lacor C 2007 Influence of glottic aperture on the tracheal flow. J Biomech 40:165-172

29. Morton RW, Mitchell JP 2007 Design of facemasks for delivery of aerosol-based medication via pressurized metered dose inhaler with valved holding chamber: key issues that affect performance. J Aerosol Med 20:s29-s45

30. Schuepp KG, Jauernig J, Janssens HM, Tiddens HA, Straub DA, Stangl R, Keller M, Wildhaber JH 2005 In vitro determination of the optimal particle size for nebulized aerosol delivery to infants. J Aerosol Med 18:225-235
31. de Jongh FH, Rinkel MJ, Hoeijmakers HW 2006 Aerosol deposition in the upper airways of a child. J Aerosol Med 19:279-289

32. Baldwin DN, Pillow JJ, Stocks J, Frey U 2006 Lung-function tests in neonates and infants with chronic lung disease: tidal breathing and respiratory control. Pediatr Pulmonol 41:391-419

33. Numa AH, Newth CJ 1996 Anatomic dead space in infants and children. J Appl Physiol 80:1485-1489

34. Stocks J, Godfrey S 1978 Nasal resistance during infancy. Respir Physiol 34:233246

35. Stocks J, Henschen M, Hoo AF, Costeloe K, Dezateux C 1997 Influence of ethnicity and gender on airway function in preterm infants. Am J Respir Crit Care Med 156:1855-1862

36. Zhang Z, Kleinstreuer C 2004 Airflow structures and nano-particle deposition in a human upper airway model. J Comput Phys 198:178-210

37. Sung SJ, Jeong SJ, Yu YS, Hwang CJ, Pae EK 2006 Customized three-dimensional computational fluid dynamics simulation of the upper airway of obstructive sleep apnea. Angle Orthod 76:791-799 